\title{
Ductal eccrine carcinoma of the axilla: a diagnostic pitfall ${ }^{*}$
}

\author{
Maria Helena Toda Sanches de Brito ${ }^{1} \quad$ Cecília Silva Nunes de Moura Dionísio ${ }^{2}$ \\ Joana Cintia Monteiro Ferreira ${ }^{3} \quad$ Maria Joaninha Madalena de Palma Mendonça da Costa Rosa ${ }^{3}$ \\ Fernando Petrucci Bernardo e Cunha ${ }^{3}$ Maria Manuela Antunes Pecegueiro da Silva Garcia ${ }^{2}$
}

DOI: http:/ /dx.doi.org/10.1590/abd1806-4841.20175369

\begin{abstract}
Ductal eccrine carcinoma (DEC) is a rare sweat gland carcinoma with ductular differentiation. Clinically, it is characterized by a slowly growing, hardened plaque or nodule predominantly located on the head and neck. Histologically, DEC shares similar features to invasive breast carcinoma, thus causing great diagnostic challenges. We report a 69-year-old woman who presented with a hardened plaque on the axilla. A skin biopsy was performed and metastatic invasive breast carcinoma could not be ruled out. Complete excision and further workup were subsequently conducted, leading to the diagnosis of estrogen receptor positive DEC with associated axillary lymph node metastases. The patient received adjuvant radiotherapy to the left axilla and was started on oral letrozole. She is disease-free 14 months after initial diagnosis.
\end{abstract}

Keywords: Axilla; Carcinoma, ductal; Sweat gland neoplasm

\section{INTRODUCTION}

Ductal eccrine carcinoma (DEC) is an extremely rare malignant adnexal tumor of eccrine origin. ${ }^{1-3}$ It is more frequently located on the head and neck, but cases on the trunk and extremities have also been described. ${ }^{4}$ Because of its striking histologic homology to invasive breast carcinoma, differential diagnosis can be challenging, particularly on unusual anatomic sites such as the breast or axilla., ${ }^{2,5-7}$ We report a case of DEC of the axilla with associated axillary lymph node metastases.

\section{CASE REPORT}

A 69-year-old Caucasian woman presented with an asymptomatic hardened plaque on the left axilla that had been slowly growing for 2 years. It consisted of a well-demarked erythematous-violaceous plaque, measuring $26 \times 11 \mathrm{~mm}$, without an underlying palpable mass (Figure 1). Both breasts were clinically normal.

An incisional skin biopsy was performed, and it showed dermal infiltration by small nests and ductal structures lined by atypical cuboidal epithelial cells embedded in a dense, desmoplastic stroma (Figure 2). The neoplastic cells were polygonal with centrally placed nuclei and abundant eosinophilic cytoplasm. No mitoses were seen (Figure 3). Immunohistochemistry was strongly positive for estrogen receptor and cytokeratin 7 (Figure 4). This morphology was thought to be suggestive of metastatic invasive breast carcinoma of no special type. However, further investigation with mammography and breast magnetic resonance detected no alterations.

Referral was subsequently made to our institution, and the patient underwent wide excision of the axillary lesion and sentinel lymph node biopsy. The histologic findings of the surgical specimen were identical to the previous biopsy. The tumor invaded the subcutis and excision was complete. No perineural or lymphovascular invasions were observed. In light of the morphological and immunohistochemical features of the tumor, and the absence of detectable breast carcinoma, final diagnosis of DEC rather than invasive breast carcinoma was made.

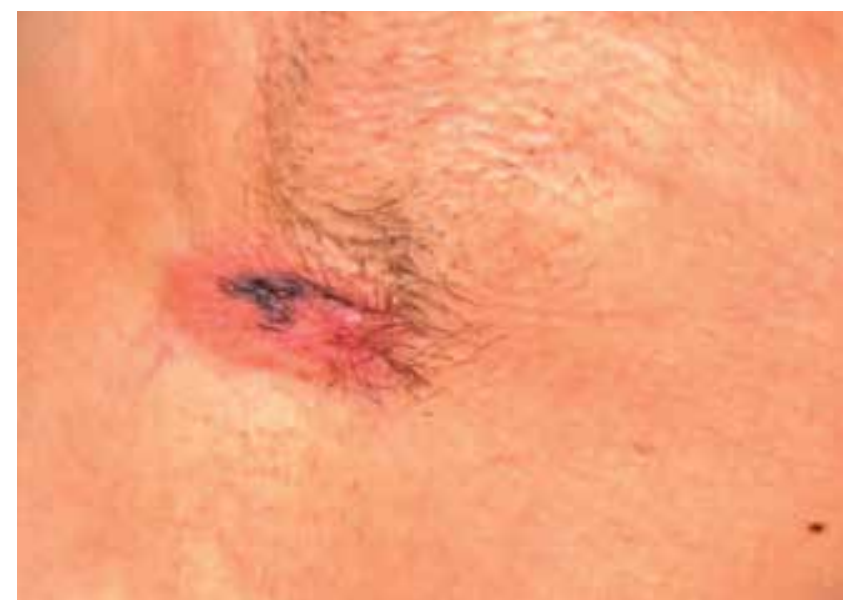

Figure 1: Clinical presentation of the erythematous-violaceous hardened plaque on the left axilla

\section{Received on 13.11.2015}

Approved by the Advisory Board and accepted for publication on 21.01.2016

Study conducted at the Department of Dermatology, Santarém Hospital - Santarém, Portugal.

Financial support: none.

Conflict of interest: none.

Department of Dermatology, Santarém Hospital - Santarém, Portugal.

Department of Dermatology, Instituto Português de Oncologia de Lisboa - Lisboa, Portugal.

Department of Pathology, Instituto Português de Oncologia de Lisboa - Lisboa, Portugal. 
Left axillary sentinel lymph node biopsy was positive, and subsequently left axillary lymph node dissection was performed, revealing metastases in 3 of the 11 lymph nodes resected (Figure 5). Computed tomography scan and positron emission tomography excluded the presence of further metastases or other primary tumors. The patient received adjuvant radiotherapy at the left axilla (total dose 60 Gy), and started oral letrozole $2.5 \mathrm{mg}$ daily. After 14 months of follow-up, she remains disease-free, under letrozole therapy.

\section{DISCUSSION}

Sweat gland carcinomas (SGC) are rare malignancies, accounting for $<1 \%$ of all reported tumors. ${ }^{5}$ Classification of these tumors is complex, due to the existence of a large number of rare entities, sometimes with overlapping features, and a multiplicity of terms used to designate the same neoplasms. ${ }^{5,8}$ To date, there is still no consensus regarding their nomenclature and classification. ${ }^{5,8}$

DEC, also reported as syringoid eccrine carcinoma, syringomatous carcinoma, eccrine epithelioma, malignant syringoma, and

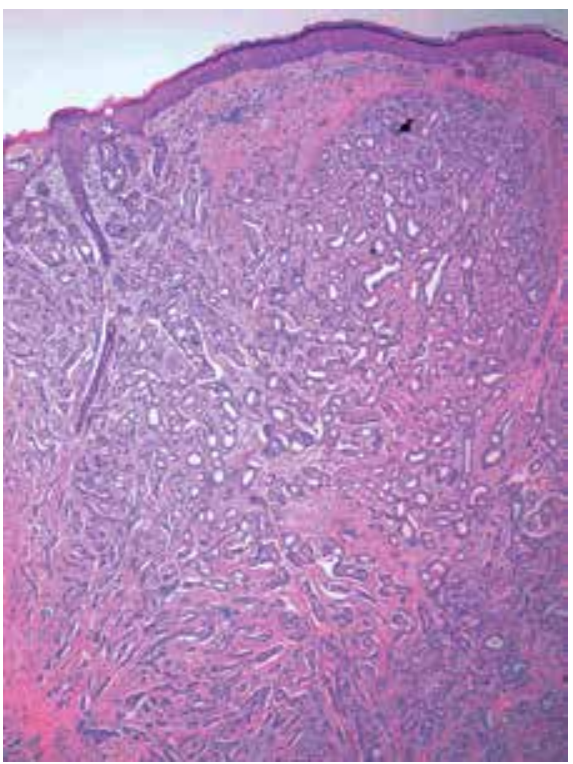

FIGURE 2: Histopathology showing neoplastic tubular and ductal structures, embedded in a dense sclerosing stroma, invading the entire dermis in a haphazard fashion (H\&E, x100)

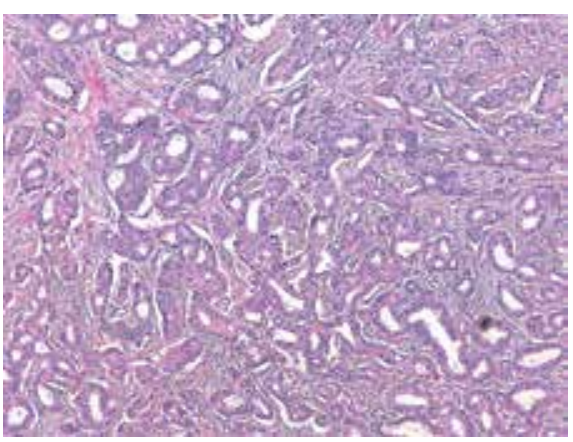

Figure 3: High-power view showing anastomosing ductal structures, lined by atypical cuboidal cells with moderate amount of eosinophilic cytoplasm and centrally placed nuclei, infiltrating into a desmoplastic stroma. No mitoses are seen (H\&E, x200)

basal cell tumor with eccrine differentiation, is an extremely rare SGC with eccrine origin and ductal differentiation. ${ }^{1-4,8}$ Fewer than 50 cases have been reported under the name of DEC and its synonyms. ${ }^{7}$

Clinically, DEC usually presents as a slowly growing, ill-defined, hardened nodule or plaque that can measure up to $10 \mathrm{~cm}$. It has a predilection for the head and neck, although cases on the trunk and extremities have also been described, and occurs mostly in middle-aged to elderly adults of both sexes. ${ }^{1,2,4,5}$

Histologically, DEC is centered on the dermis and shows a markedly infiltrative growth pattern, often extending into the subcutaneous tissue. ${ }^{3,7,8}$ The tumor is primarily composed of thin strands and nests of cuboidal epithelium with variable degrees of glandular differentiation. ${ }^{2}$ Intracytoplasmic lumina are sometimes 
CHART 1: Clinical and histopathological features of ductal eccrine carcinoma (DEC) and its main differential diagnosis: squamoid ductal eccrine carcinoma (SDEC), microcystic adnexal carcinoma (MAC) and metastatic breast carcinoma

\begin{tabular}{|c|c|c|}
\hline Lesion & Common features in DEC, $\mathrm{S}$ & $\begin{array}{l}\text { topathological features } \\
\text { DEC and MAC: }\end{array}$ \\
\hline & $\begin{array}{l}\text { Slowly growing, ill-defined, hardened nodule or plaque } \\
\text { Aggressive local behavior, tendency for local recurrence }\end{array}$ & $\begin{array}{l}\text { Poorly circumscribed } \\
\text { Markedly infiltrative growth pattern, involving the derm } \\
\text { and extending commonly to the underlying structures } \\
\text { Thin strands and nests of cells with focal ductal differentiatio } \\
\text { Intracytoplasmic lumina may be evident } \\
\text { Perineural invasion is common } \\
\text { Desmoplastic stroma }\end{array}$ \\
\hline DEC & $\begin{array}{l}\text { Usually not ulcerated } \\
\text { Predilection for the head and neck (particularly the scalp) } \\
\text { Predominates in middle-aged to elderly patients of both sexes } \\
\text { Metastatic potential? (conflicting data in the literature) }\end{array}$ & $\begin{array}{l}\text { Purely ductal differentiation } \\
\text { Cellular atypia and mitoses are uncommon }\end{array}$ \\
\hline SDEC & $\begin{array}{l}\text { May show ulceration, erosion or crusting } \\
\text { Predilection for the head and neck or extremities } \\
\text { Predominates in elderly male patients } \\
\text { Low metastatic potential }\end{array}$ & $\begin{array}{l}\text { Both ductal and squamous differentiation: squamous compc } \\
\text { nent with keratinization towards the surface, ductal different } \\
\text { ation in deeper areas } \\
\text { Cellular atypia and mitoses are variable, but often conspicuou } \\
\text { Ulceration and necrosis are common }\end{array}$ \\
\hline MAC & $\begin{array}{l}\text { Usually not ulcerated } \\
\text { Predilection for the head and neck (particularly the perioral and } \\
\text { periocular areas) } \\
\text { Predominates in middle-aged to elderly patients of both sexes } \\
\text { Low metastatic potential }\end{array}$ & $\begin{array}{l}\text { Both ductal and follicular differentiation: keratinous micr } \\
\text { cysts in superficial part, ductal differentiation in deeper areas } \\
\text { Cellular atypia and mitoses are uncommon }\end{array}$ \\
\hline $\begin{array}{l}\text { Metastatic } \\
\text { breast } \\
\text { carcinoma }\end{array}$ & $\begin{array}{l}\text { Wide range of clinical presentations, may resemble DEC } \\
\text { Predilection for the trunk } \\
\text { Predominates in middle-aged to elderly women } \\
\text { Past medical history and/or clinical and radiological examina- } \\
\text { tion of the breasts consistent with breast carcinoma }\end{array}$ & Histological features indistinguishable from those of DEC. \\
\hline
\end{tabular}

evident. Pleomorphism and mitotic activity are variable features, but are usually not marked. ${ }^{3,8}$ The stroma is characteristically desmoplastic and perineural and lymphovascular invasion are commonly present. ${ }^{4,7,8}$

On immunohistochemistry, tumor cells are cytokeratin positive, expressing mostly simple epithelial cytokeratins (CK7, -8, -18, and -19). They may also express estrogen and progesterone receptors, CEA, c-erbB-2, S-100, and GCDFP-15 to varying degrees. ${ }^{2,4,9}$

The main differential diagnosis for DEC includes other eccrine adnexal tumors showing ductal differentiation, primarily squamoid ductal eccrine carcinoma and microcystic adnexal carcinoma, and metastatic adenocarcinomas, particularly from the breast (Chart 1). ${ }^{2}$ DEC shows striking histologic similarities to invasive breast carcinoma, including expression of estrogen receptors, and immunohistochemistry is of little value in the differential diagnosis. ${ }^{2,5}$ In our case, unusual location of the tumor on the axilla of a female patient further challenged the diagnosis. The final diagnosis often relies on the exclusion of other entities through a careful clinical assessment and extensive work-up of the patient. . $2,38^{2}$

Because of its rarity, a standard method of treatment for DEC has not been established. ${ }^{2,5}$ Wide surgical excision is the treatment of choice for localized lesions. ${ }^{1,7}$ In metastatic disease, clinical benefit has been documented with both tamoxifen (in hormone receptor positive DEC) and a number of chemotherapy regimens, as well as radiotherapy. ${ }^{5,710}$ Prophylactic lymph node excision should not be performed. ${ }^{1}$

Regarding prognosis, there is conflicting data published in the literature. Some authors document a good prognosis and rare metastasis, while others report a poor prognosis, with up to $50 \%$ of patients developing metastasis to lymph nodes or viscera, and cases with visceral metastases being almost invariably fatal. ${ }^{1,3,5,9}$ Local recurrence is common and is seen in up to $70-80 \%$ of all cases. ${ }^{1,2,7,8}$ 


\section{REFERENCES}

1. Frouin E, Vignon-Pennamen MD, Balme B, Cavelier-Balloy B, Zimmermann $\mathrm{U}$, Ortonne $\mathrm{N}$, et al. Anatomoclinical study of 30 cases of sclerosing sweat duct carcinomas (microcystic adnexal carcinoma, syringomatous carcinoma and squamoid eccrine ductal carcinoma). J Eur Acad Dermatol Venereol. 2015;29:1978-94.

2. Park BW, Kim SI, Lee KS, Yang WI. Ductal eccrine carcinoma presenting as a Paget's disease-like lesion of the breast. Breast J. 2001;7:358-62.

3. Obaidat NA, Alsaad K0, Ghazarian D. Skin adnexal neoplasms-part 2: an approach to tumours of cutaneous sweat glands. J Clin Pathol. 2007;60:145-59.

4. Sidiropoulos M, Sade S, Al-Habeeb A, Ghazarian D. Syringoid eccrine carcinoma: a clinicopathological and immunohistochemical study of four cases. J Clin Pathol. 2011;64:788-92

5. McLean SR, Shousha S, Francis N, Lim A, Eccles S, Nathan M, et al. Metastatic ductal eccrine adenocarcinoma masquerading as an invasive ductal carcinoma of the male breast. J Cutan Pathol. 2007;34:934-8.

6. Bindra A, Bhuva V, Jasani J, Chauhan S, Shukla R, Darad D. Ductal eccrine carcinoma - a sweat gland carcinoma with ductular differentiation - a case report. Int J Biol Med Res. 2012;3:1862-4.

7. Ballardini P, Margutti G, Pedriali M, Querzoli P. Metastatic syringoid eccrine carcinoma of the nipple. Int Med Case Rep J. 2012;5:45-8.

8. Cardoso JC, Calonje E. Malignant sweat gland tumours: an update. Histopathology. 2015;67:589-606

9. Ohnishi T, Kaneko S, Egi M, Takizawa H, Watanabe S. Syringoid eccrine carcinoma: report of a case with immunohistochemical analysis of cytokeratin expression. Am J Dermatopathol. 2002;24:409-13.

10. Schröder U, Dries V, Klussmann JP, Wittekindt C, Eckel HE. Successful adjuvant tamoxifen therapy for estrogen receptor-positive metastasizing sweat glandadenocarcinoma: need for a clinical trial? Ann Otol Rhinol Laryngol. 2004;113:242-4.
MAILING ADDRESS:

Maria Helena Toda Sanches de Brito

Avenida Bernardo Santareno, 2005-177

Santarém, Portugal.

Email: helenatodabrito@gmail.com

How to cite this article: Brito MHTS, Dionísio CSNM, Ferreira JCM, Rosa MJMPMC, Cunha FPB, Garcia MMAPS. Ductal eccrine carcinoma of the axilla: a diagnostic pitfall. An Bras Dermatol. 2017;92(2):239-42. 